\title{
Bioprospecting of some medicinal plants explored for antifungal activity
}

\author{
Kumara Shanthamma Kavitha and Sreedharamurthy Satish* \\ Department of Studies in Microbiology, Herbal Drug Technological Laboratory, University of Mysore, Manasagangotri, Mysore 570006 Karnataka, India.
}

\begin{abstract}
In the present study, evaluation of different plant parts of fifteen medicinal plants belonging to different families have been screened for in vitro efficacy of antifungal activity against phyto pathogenic (Aspergillus and $\mathrm{Fu}$ sarium species) as well as human pathogenic fungi (Candida albicans and Microsporum species) using agar well diffusion assay. The results showed that among fifteen medicinal plants, crude extracts of different solvents viz., petroleum ether, chloroform, ethyl acetate and methanol tested for antifungal activity, twelve plants were found to be effective against one or the other test fungi, among these plants, solvent extracts of Callistemon lanceolatus showed significant activity against C. albicans, Microsporum gypseum, Cordia dichrotoma leaves extracts exhibited significant activity against $A$. niger, A. flavus and C. albicans. Sphaeranthus indicus L. whole plant extracts exhibited significant activity against Aspergillus spp., C. albicans and Microsporum canis. Leaves extracts of Vitex negundo exhibited significant activity against $A$. niger, A. flavus, $F$. verticillioides, C. albicans and moderate activity against F. crookwellense. Extracts of
\end{abstract}

Butea monosperma exhibited significant to moderate activity against all test pathogens except $C$. albicans. The obtained results imparts a preliminary piece of significant information regarding the antifungal potentiality of screened medicinal plants with crude solvent extracts, which could be exploit for further isolation and investigation of antifungal agents for crop diseases management and human health.

Address for Correspondence:

Dr. Sreedharamurthy Satish, Department of Studies in Microbiology, Herbal Drug Technological Laboratory, University of Mysore, Manasagangotri, Mysore-570 006, Karnataka, India. and Visiting Scholar, Department of Plant Pathology, University of Georgia, Athens 30602, USA.

Phone no: +91-9448323129, +1-706-715-1643

E-mail: satish.micro@gmail.com, satish@uga.edu

DOI : 10.5530/pj.2016.1.13

\section{INTRODUCTION}

Plants are persistently exposed and threatened by diverse pathogenic microorganisms such as fungi, bacteria, nematodes, viruses etc, present in their environments. More than 800 million people in developing countries do not have adequate food supplies and at least $10 \%$ of food is lost due to plant diseases. During food grains storage, nearly up to $30 \%$ loss is caused grains due to microbial bio-deterioration. ${ }^{1}$ The World's annual crop losses as a consequence of disease have been estimated at 25,000 million US dollars; of this fungi carried through seeds forms the major pathogen. ${ }^{2-3}$ Compared to other parasites, fungi are significant destroyers of foodstuffs and grains during storage, rendering them unfit for human consumption by retarding their nutritive value and often by producing mycotoxins. ${ }^{4-5}$ resulting in terrible impact with regard to diseases and crop production losses. ${ }^{6}$ Till date, more than 100,000 fungal species are considered as natural contaminant of agricultural and food products. ${ }^{7}$ Even though, effective management of plant diseases caused by seed borne fungi can be achieved by the application of fungicides, the same does not holds effective for grains due to pesticide toxicity. ${ }^{8}$ As a result, the existence of microbial resistance has stipulated as a serious problem in agricultural fields ${ }^{9}$ along with many more side effects. The toxicity of synthetics can only be reduced by persistent search for effective, new and safer green fungicides, pesticides as for human and environmental concern. ${ }^{10}$

Fungi are also responsible for causing severe threat to human mankind and form one of the major causes of morbidity and mortality. ${ }^{11}$ In recent decades, fungal infections in human beings, ranges from superficial to deeply invasive or disseminated, and have been increased fiercely. The humid weather, over population and poor hygienic conditions are ideally favors for the fungal growth and these factors are more important in a tropical country like India. As a part and parcel, increased fungal infections can be observed in an immune-compromised population such as organ transplant recipients, cancer and HIV/AIDS patients due prolonged use of drugs, resistance and its toxicity. This will again render the development of multi-drug resistant strains, which has become global menace. The production and availability of antifungal drugs in a market is less in comparable with antibacterial drugs. Therefore, there is a need to search for new antifungal drugs. The ramification of use of synthetic antifungal agents against plant and human diseases has created awareness among the researchers worldwide, and thus much of the research areas are focused on development of novel, potent and green principle based antifungal agents using medicinal plants, owing to their different mode of action, different target sites with minimized side effects than the conventional available drugs. Though, plants represent a natural repository consists of chemotherapeutants with myriad biological potentiality can provide valuable sources of natural antimicrobial agents, and also by knowing the facts that plant can synthesize inexhaustible bioactive compounds with bearing characteristic chemical structures. Screening of crude plant extracts is a preliminary step to check the biological efficacy rather than screening of pure compounds isolated from plants. Thus, the present study designed to evaluate the in vitro antifungal activity of fifteen medicinal plants crude extracts against both plant and human pathogenic fungi.

\section{MATERIALS AND METHODS}

\section{Plant sample collection}

Fifteen medicinal plant species were collected in and around Mysore district of Karnataka, India. The Voucher specimen of plant material has been deposited and authenticated at the National Ayurveda Dietetics Research Institute, Bangalore. The collected healthy and mature plant materials were washed thoroughly under running tap water for 2-3 times and once with distilled water and dried at room temperature. The dried plant materials were grounded to a coarse powder and then used for extraction using cold extraction method.

\section{Preparation of plant extracts}

Fifty grams of shade-dried and coarsely powdered plant material was extracted successively with $250 \mathrm{ml}$ each of petroleum ether, chloroform, ethyl acetate and methanol in the increasing order of their polarity and 
kept in a shaker for $24-48 \mathrm{~h}$. The extracts thus obtained were filtered with Whatman No. 1 filter paper and the filtrate was evaporated to dryness. After complete solvent evaporation, extracts were stored at $4^{\circ} \mathrm{C}$ in airtight amber bottles for further use. ${ }^{12}$

\section{Test pathogens}

Plant pathogenic fungi includes Aspergillus spp. such as A. flavus oryzae, A. niger and Fusarium spp. such as F. crookwellense, F. sporotrichioides, F. verticillioides were selected. The cultures were maintained on PotatoDextrose Agar (PDA) medium. Human pathogenic fungi such as Candida albicans, Microsporum canis and Microsporum gypsum were preserved on Sabouraud's agar (SA) medium employed for the assay.

\section{Antifungal assay by Agar well diffusion method}

Antifungal activity of different test solvent extracts (petroleum ether, chloroform, ethyl acetate and methanol) was determined by agar well diffusion method. ${ }^{13}$ An aliquot of $100 \mu$ of each fungal spores suspension to be tested containing approximately $10^{5}$ spores $/ \mathrm{ml}$, was spread with a sterile swab on Potato dextrose agar and Sabouraud's agar plates for plant and human pathogenic fungi respectively. Wells of $8 \mathrm{~mm}$ diameter were made on agar medium using sterile cork borer and the test solvent extracts were added into the wells and allowed to diffuse at refrigerator for $2 \mathrm{~h}$. The plates were then incubated at in the upright position at room temperature for 3-4 days. After incubation, the diameter of the inhibition zone $(\mathrm{mm})$ was measured. Triplicates were maintained and the data were expressed as mean \pm standard error. Bavistin and miconozole serves as reference antibiotics.

\section{RESULTS}

In the present investigation, antifungal activity of fifteen medicinal plants of different plant parts (Table 1) with different solvents by cold extraction method was evaluated by agar well diffusion method at $100 \mu \mathrm{g} /$ $\mathrm{ml}$ concentration against plant pathogenic fungi such as Aspergillus and Fusarium species and human pathogenic fungi such as Candida albicans, Microsporum canis and Microsporum gypsum (Table 2). Among fifteen medicinal plants screened for antifungal activity against five plant pathogenic and three human pathogenic fungi with four different solvent viz., petroleum ether, chloroform, ethyl acetate and methanol crude extracts, twelve plants were found to bear antifungal potential and were effective against one or the other test fungi, wherein remaining test plants were completely ineffective against all test fungi.

Petroleum ether leaves extracts of Andrographis paniculata (Burm. F.) Wall. Ex. Nees. showed least activity against F. crookwellense, F. sporotrichioides and moderate activity with chloroform, ethyl acetate and methanol extracts. Whereas petroleum ether, chloroform extracts showed least activity and ethyl acetate, methanol extracts showed significant activity against $A$. niger. All the test solvent extracts did not show any inhibition against $A$. flavus, F. verticillioides, Candida albicans, Microsporum canis and M. gypseum. Only ethyl acetate and methanol seeds extracts of Annona squamosa L. showed least activity against $F$. verticillioides whereas remaining test solvent extracts did not show any antifungal activity against test fungi. Petroleum ether flower extract of Butea monosperma (Lam.) Tuberf. showed moderate activity against A. niger, A. flavus, F. crookwellense, F. sporotrichioides but there was no zone of inhibition against $F$. verticillioides, Candida albicans, Microsporum canis and M. gypseum. Chloroform extract showed significant activity against A. niger, A. flavus, F. crookwellense, F. verticillioides, Microsporum canis, M. gypseum and moderate activity against F. sporotrichioides, but no activity was found for Candida albicans. Ethyl acetate extract showed moderate activity against $A$. flavus, F. crookwellense, F. sporotrichioides and $M$. canis but no activity was found against $A$. niger, F. verticillioides, $C$. albicans and M. gypseum. Methanol extract showed significant activity
Table 1: Test medicinal plants employed for antimicrobial activity

\begin{tabular}{ccc|}
\hline Medicinal plants & Family & Plant part used \\
\hline Andrographis paniculata (Burm. F.) & Acanthaceae & Leaves \\
Wall. Ex. Nees. & Annonaceae & Seed \\
Annona squamosa L. & Convolvulaceae & Flower and twig \\
Argyreia nervosa (Burm.f.) Bojer & Asclepiadaceae & Whole plant \\
Asclepias curassavica L. & Fabaceae & Flower \\
Butea monosperma (Lam) Tuberf. & Myrtaceae & Leaves \\
Callistemon lanceolatus DC. & Rubiaceae & Leaves \\
Canthium parvilorum Lam. & Vitaceae & Leaves \\
Cissus quadrangularis Linn. & Boraginaceae & Leaves \\
Cordia dichrotoma Forster F. & Moraceae & Leaves \\
Ficus religiosa Linn. & Sterculiaceae & Leaves \\
Helicteres isora L. & Moringaceae & Leaves \\
Moringa oleifera Lam. & Asteraceae & Whole plant \\
Sphaeranthus indicus Linn. & Moraceae & Leaves \\
Streblus asper Lour. & Verbenaceae & Leaves \\
Vitex negundo L. & &
\end{tabular}

against F. verticillioides and M. gypseum, moderate activity against A. niger, F. crookwellense, F. sporotrichioides whereas no activity was observed against A.flavus, C. albicans and M. canis when compared to reference antibiotics.

None of the test solvent leaves extracts of Callistemon lanceolatus DC. showed antifungal activity against plant pathogenic fungi whereas significant activity was observed with all the test solvent extracts against C. albicans and chloroform, ethyl acetate extracts showed significant and moderate activity against $M$. canis respectively but no activity was observed against $M$. gypseum with the test solvent extracts. Petroleum ether leaves extract of Canthium parvilorum Lam. showed least activity against $A$. flavus only, but no activity was found against other test pathogens. Chloroform extract displayed no antifungal activity against the test pathogenic fungi. Ethyl acetate showed least activity against $F$. crookwellense, whereas the other test pathogens were found to be ineffective. Methanol extracts showed least activity against $A$. niger, A. flavus and $F$. crookwellense but the extract was ineffective against rest of the test pathogens.

Leaves extracts of Cissus quadrangularis L. showed least activity against A. flavus compared to reference antibiotic whereas the test solvent extracts were found to be ineffective against other test plant and human pathogenic fungi. Petroleum ether, chloroform and methanol leaves extracts of Cordia dichotoma Forster F. exhibited moderate to significant activity against $A$. niger whereas ethyl acetate extract did not show any antifungal activity. Petroleum ether, chloroform extracts showed moderate and ethyl acetate and methanol extracts exhibited significant activity against $A$. flavus. Moderate activity was observed with the test solvent extracts against $F$. crookwellense whereas only ethyl acetate and methanol extracts was found to be significant against F. sporotrichioides. No activity was found against $F$. verticillioides, M. canis and M. gypseum whereas $C$. albicans was significantly inhibited with the test solvent extracts. Leaves extracts of Ficus religiosa L. did not show any antifungal activity against plant pathogenic fungi whereas only petroleum ether and methanol extracts showed moderate and significant antifungal activity against $C$. albicans whereas other test solvent extracts did not showed any inhibition zone. Also, M. canis and M. gypseum was found to be resistant to all test solvent extracts. Chloroform and ethyl acetate extracts of Moringa oleifera Lam. leaves exhibited significant antifungal activity against $A$. niger. Moderate activity was observed with petroleum ether, chloroform, ethyl acetate extracts against $F$. crookwellense and also moderate was exhibited against F. sporotrichioides with petroleum ether, chloroform and metha- 


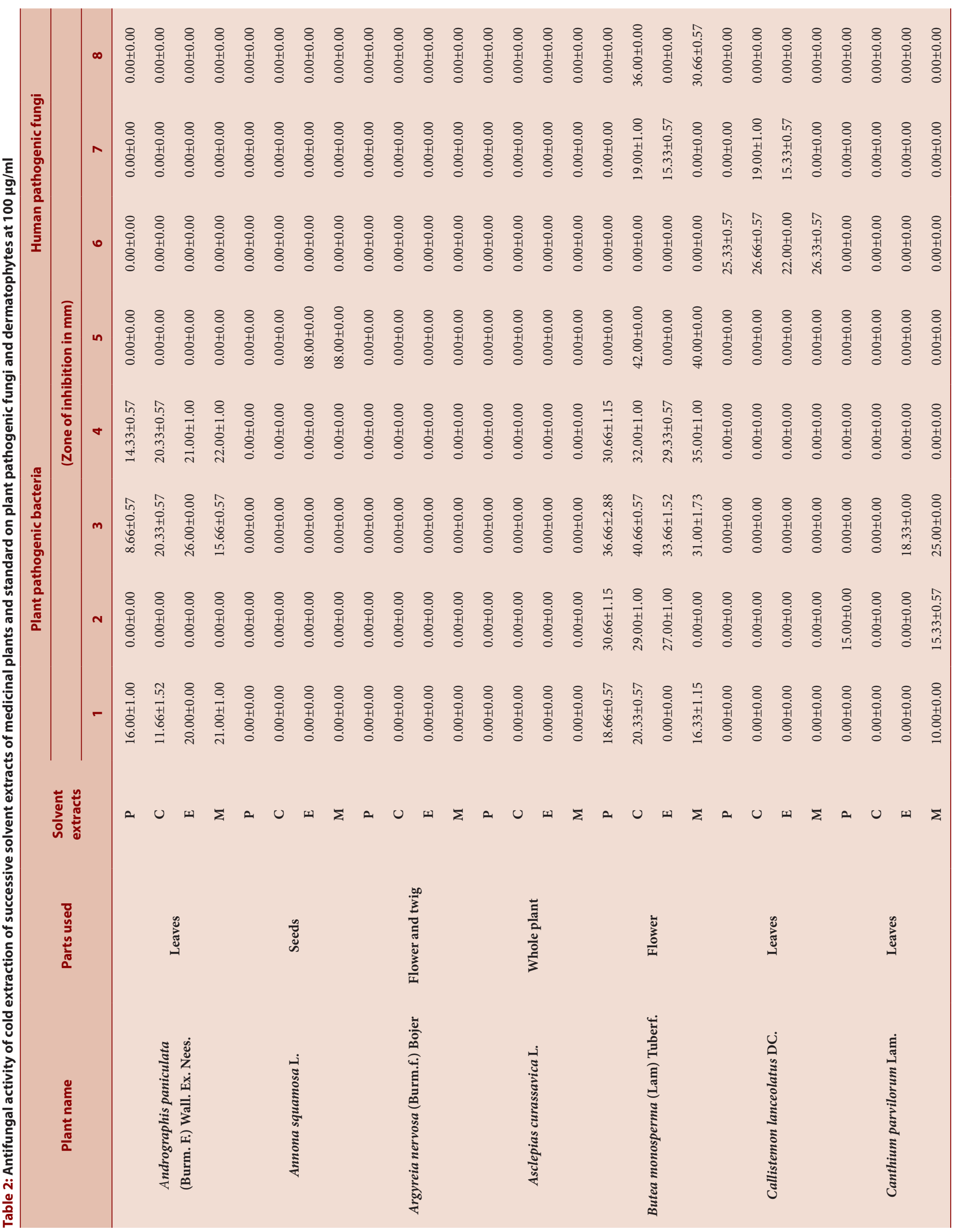




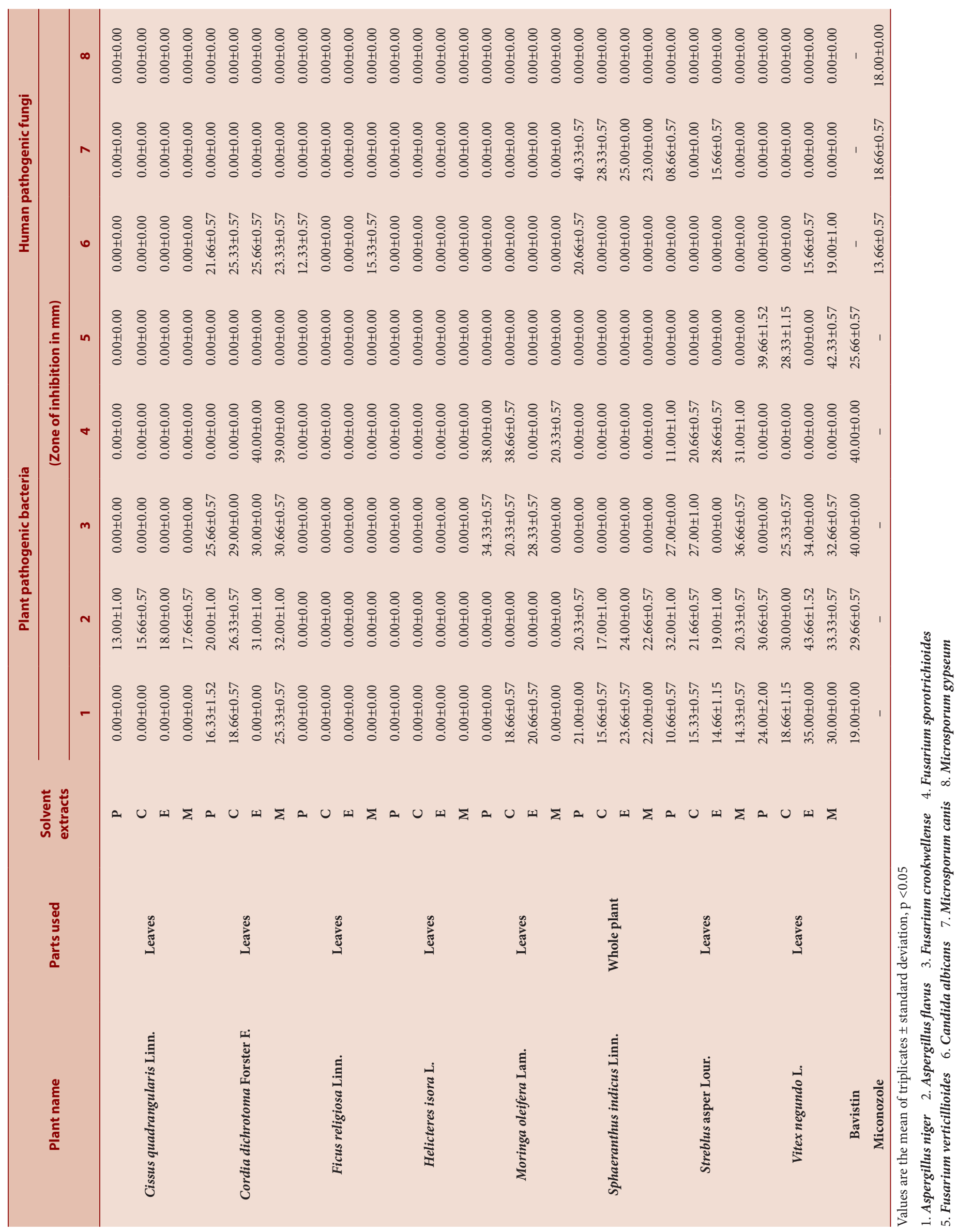


nol extracts. None of the test solvent extracts showed antifungal activity against $A$. flavus, F. verticillioides, C. albicans, M. canis and M. gypseum.

Sphaeranthus indicus Linn. whole plant petroleum ether, chloroform, ethyl acetate and methanol extracts exhibited significant activity and least activity with chloroform extract against $A$. niger. Moderate activity was observed against $A$. flavus with all the test solvent extracts. Only ethyl acetate extract showed significant activity against C. albicans. All the test solvent extracts exhibited significant activity against Microsporum canis, whereas none of the test solvent extracts showed antifungal activity against $F$. crookwellense, F. sporotrichioides, F. verticillioides and M. gypseum. Streblus asper Lour. leaves showed least antifungal activity against Aspergillus niger and moderate activity against $A$. flavus. Moderate zone of inhibition was observed with petroleum ether, chloroform and methanol extracts against F. crookwellense. Least and moderate antifungal activity was observed with petroleum ether, chloroform and ethyl acetate, methanol extracts respectively against $F$. sporotrichioides. Only petroleum ether and ethyl acetate extracts showed least activity against $M$. canis whereas no zone of inhibition was found against $F$. verticillioides, C. albicans and M. gypseum.

Leaves of Vitex negundo L. exhibited significant antifungal activity against $A$. niger and A. flavus with all the test solvent extracts, whereas moderate activity was found against $F$. crookwellense with chloroform, ethyl acetate and methanol extracts but there was no zone of inhibition with petroleum ether extract. All solvent extracts showed significant activity against $F$. verticillioides except ethyl acetate extract. Only ethyl acetate and methanol extracts showed significant activity against C. albicans in comparison with reference antibiotic. There was no antifungal activity against F. sporotrichioides, M. canis and M. gypseum. Four different test solvent extracts of Argyreia nervosa (Burm. F.) Bojer. flower \& twig, whole plant of Asclepias curassavica L. and leaves of Helicteres isora $\mathrm{L}$. were found to be ineffective against all the test pathogenic plant pathogenic and human pathogenic fungi.

\section{DISCUSSION}

In current scenario, there is wide search for new effective antimicrobial agents from natural sources. Numerous studies have been carried out with the various plants extracts for exploration of their antimicrobial activity against pathogenic microorganisms. Thus the present investigation indicates that the majority of the plants tested are an important source of antifungal compounds that may provide renewable sources of useful antifungal drugs against plant and human pathogenic fungi. In accordance with our obtained results, the investigation by Radha et al., ${ }^{14}$ revealed significant inhibitory activity against Candida albicans and Aspergillus flavus with methanol leaf and acetone stem extracts of Andrographis paniculata respectively. Another study revealed antifungal against Penicillum sp and A. flavus but did not show activity against C. albicans, A. niger, A. oryzae. ${ }^{15}$ Annona squamosa seed extracts against test pathogenic fungi, exhibited scanty reports. Significant antifungal activity was reported against Trichophyton rubrum, A. niger, A. flavus and Candida albicans. ${ }^{16}$ Two fractions (CVP-1 and CVP-2) of roots and flowers of Butea monosperma (Lam.) were tested against Alternaria, Fusarium and A. flavus. Fraction CVP-1 was found significant activity against Fusarium followed by Alternaria and A. flavus, fraction CVP-2 exhibited significant activity against Alternaria, Fusarium and least activity against $A$. flavus. ${ }^{17}$ In comparable with our results with Callistemon lanceolatus, the moderate antifungal activity against Candida albicans and A. niger was found with petroleum ether, ethyl acetate but no activity was found with methanol extracts of Callistemon citrines. ${ }^{18}$ According to Merinal and Boi, ${ }^{19}$ showed that the ethanol leaf extract of Cissus quadrangularis with maximum inhibition against Candida albicans followed by Aspergillus flavus and Fusarium sp. Diethyl ether extract exhibited significant activ- ity against Aspergillus flavus but there was no inhibitory effect on Fusarium solani and also the aqueous extract did not show any inhibitory zone against tested pathogens. The inhibitory activity against Candida albicans and Candida trophicalis have been reported. ${ }^{20}$ by The use of solvents might have influenced the phyto-compounds extraction responsible for antifungal activity. Suman et al. ${ }^{21}$ reported significant activity against $A$. niger and C. albicans with methanol leaf extract. Whereas, no inhibitory activity was recorded against Aspergillus niger, Penicillium spp., Scytalidium spp. ${ }^{22}$ with leaf extracts of Cordia myxa in comparison with our data using C. dichotoma. Aqueous leaf extract showed significant activity against Aspergillus niger and moderate activity against Candida albicans. ${ }^{23}$ Ramakrishnaiah and Hariprasad, ${ }^{24}$ reported least activity with methanol leaf extract against $A$. niger whereas no activity was observed with diethyl ether extract. In accordance with the obtained results in our study infers that solvent might have influenced in the inhibitory activity. Steam distillate of Moringa oleifera Lam, was evaluated for antifungal activity $^{25}$ resulted in zone of inhibition against $A$. niger followed by $A$. oryzae, $A$. terreus and $A$. nidulans. Devendra et al. ${ }^{26}$ reported antifungal activity against Aspergillus niger and Candida albicans with leaf extract. In another study, ${ }^{27}$ the antifungal activity of methanol and ethanol leaf extracts against Penicillum sp and Aspergillus sp resulted in the growth was found to be decreased with increasing concentration of the extracts. Significant activity using ethanol leaves extract of Sphaeranthus indicus against Candida albicans was reported.$^{28}$ In earlier investigation, ${ }^{29}$ showed significant activity against Microsporum gypseum compared to standard antibiotic with flower extract whereas moderated activity was observed against A. fumigates. Though all the parts of this plant has showed significant antifungal activity demonstrated from the earlier reports, whole plant extracts in our study was also successful in revealing the antifungal activity against test pathogens. Another study reported anti-candidal activity with leaf extract and exhibited potential controlling germ tube production by C. albicans adhesion. ${ }^{30}$ The present study reports the moderate to least antifungal activity against Aspergillus spp. Fusarium spp. and Microsporum spp. is the first report as per the literature survey. Least antifungal activity was observed against Candida albicans but no activity was found against $A$. flavus, A. niger and Trycophyton mentegrophyte. ${ }^{31}$ The variation among the results may be due to the location and duration of plant sample collection.

In accordance with obtained results, Devi et al., ${ }^{32}$ reported least activity against Trichophyton rubrum with methanol fruit extract of Argyreia nervosa whereas ethyl acetate extract did not show any activity. Badgujar et al., ${ }^{33}$ reported significant activity against Cryptococcus neoformans, Candida tropicalis, Trychophyton rubrum, Microsporum furfure, Epidermophyton floccosum with methanol extract of stem bark of Helicteres isora whereas the petroleum ether extract showed weak antifungal activity and no reports on antifungal activity against test plant and human pathogenic fungi using leaves extracts of Asclepias curassavica and Canthium parvilorum. Since, Survey of literature revealed the insufficient research data of antifungal activity using these plants; we made an attempt to disclose the antifungal activity against test pathogenic fungi.

\section{CONCLUSION}

The reconnaissance of literature survey on antifungal activity indicates that variety of plant species have known to possess antifungal activity. From the present study it can be concluded that the exploitation of plant extract employed in our work as antifungal agents are fewer as per the literature survey. As the present investigation has been carried out using crude plant extract against panel of phyto and human pathogenic fungi, the results obtained serve as a preliminary data with paramount importance for the search of newer bioactive compounds. Though the importance of green pesticides, fungicides and also as antibiotics over 
synthetic chemicals are gaining much interest in the current era, studies on plant extracts and its biologically active principles for antifungal activity has to be focused much in upcoming research that could serve in the maintenance of human and plant health.

\section{ACKNOWLEDGEMENTS}

The authors are pleased to thank UGC-Raman Fellowship for providing exchange program (2014-2015). Authors also express their gratitude for Rajiv Gandhi National Fellowship for providing fellowship. Authors are also thankful for DST-SERB for providing financial assistance.

\section{CONFILCTS OF INTEREST}

The authors have declared that there is no conflict of interests.

\section{ABBREVIATION USED}

C. albicans: Candida albicans, A. niger: Aspergillus niger, A. flavus: Aspergillus flavus, F. verticillioides: Fusarium verticillioides, F. crookwellense: Fusarium crookwellense, ml: millimeter, h: hours, P: Petroleum ether, E: Ethyl acetate, M: Methanol, C: Chloroform, M. gypseum: Microsporum gypseum, $\boldsymbol{\mu g}$ : micro gram.

\section{REFERENCES}

1. Satish S, Raghvendra MP, Mohan DC, Raveesha KA. In-vitro evaluation of the antifungal potentiality of Polyalthia longifolia against some sorghum grain moulds. J Agric Technol. 2010; 6(1): 135-50.

2. Agrios GN. Control of plant diseases. Plant pathology. $4^{\text {th }}$ edition. 1997 California: Academic Press.

3. Chandler J. Cost reduction in SIT programmes using exosect auto-dissemination as part of area wide integrated pest management. International Journal of Pest Control. 2005; 47(5): 257-60.

4. Koirala P, Kumar S, Yadar BK, Premarajan KC. Occurrence of aflatoxin in some of the food and feed in Nepal. Indian Journal of Medical Sciences. 2005; 59(8): 331-6.

5. Domijan A, Feraica M, Jurjevic Z, Ivil D, Cvjetkovic B. Fumonisin B1, fumonisin B2, Zearalenone and ochratoxin A contamination of maize in Croatia. Food additives and contaminants. 2005; 22(7): 677-80

6. Montesinos E. Antimicrobial peptides and plant disease control. FEMS Microbiology Letters. 2007; 1(270): 109-19.

7. Sati SC, Joshi S. Aspects of antifungal potential of ethnobotanically known medicinal plants. Res J Med Plant. 2011; 5(4): 377-91.

8. Harris CA, Renfrew MJ, Woolridge MW. Assessing the risk of pesticide residues to consumers: recent and future developments. Food additives and contamination. 2001; 18(12): 1124-9

9. Satish S, Mohana DC, Raghavendra MP, Raveesha KA. Antifungal activity of some plant extracts against important seed borne pathogens of Aspergillus sp. Journal of Agricultural Technology. 2007; 3(1): 109-19.

10. Kavitha HU, Satish S. Eco- friendly management of plant pathogens by some medicinal plant extracts. Journal of Agricultural Technology 2011; 7(2): 449-61.

11. CSIR. Wealth of India, publications \& information directory. New Delhi, India: CSIR; 1998; 164

12. Parekh J, Nair R, Chanda S. Preliminary screening of some folklore medicinal plants from western India for potential antimicrobial activity. Indian J. Pharmacol. 2005; 37(6): 408-9.
13. Govindappa M, Sadananda TS, Channabasava R, Jeevitha MK, Pooja KS, Raghavendra VB. Antimicrobial, antioxidant activity and phytochemical screening of Tecoma stans (L.) Juss. Ex Kunth. Journal of Phytology. 2011; 3(3): 68-76.

14. Radha R, Sermakkani M, Thangapandian V. Evaluation of phytochemical and antimicrobial activity of Andrographis paniculata Nees. (Acanthaceae) aerial parts. Int J Pharm \& Life Sci (IJPLS). 2011; 2(2): 562-7.

15. Rajalakshmi G, Aruna D, Bhuvaneswari B, Venkatesan RS, Natarajan A, Jegatheesan K. Prophylactic effect of Andrographis paniculata extracts against fungal species. Journal of Applied Pharmaceutical Science 2012; 2(9): 058-60.

16. Vidyasagar GM, Singh SP. A comparative antimicrobial activity of methanolic root, leaf, seed cotyledon extracts of Annona squamosa L. International Journal of Pharmacy \& Pharmaceutical Sciences. 2012; 4(5): 289.

17. Mehta JP, Pandya CV, Parmar PH, Golakiya BA. Isolation, characterization and antimicrobial activity of Butea monosperma (Lam.). Iranian Journal of Pharmacology \& Therapeutics. 2011; 10(2): 76-81.

18. Haque ME, Sultana A, Shibib BA, Islam MM. Antimicrobial, antioxidant and cytotoxic activities of Callistemon citrinus (Curtis) Skeels. Dhaka Univ J Pharm Sci. 2012; 11(1): 51-4.

19. Merinal S, Boi VSG. In vitro screening of antimicrobial potentials of Cissus quadrangularis L. Asian Journal of Plant Science and Research. 2012; 2(1) 58-62.

20. Saikia KKR, Borah WV, Kalita MC, Lahkar M. Comparative screening of antibacterial and antifungal activity of six ethno-medicinally important plants of Assam. Int J Pharm Bio Sci. 2013; 4(1): 890-8.

21. Suman R, Ruchi S, Ankita S. Phytochemical study and antimicrobial activities of Cordia dichotoma. International research Journal of Pharmacy. 2013; 4(12): 53-6.

22. Pandey B, Deshpande B, Singh S, Chandrakar V. Estimation of elemental contents of Cordia myxa and its antimicrobial activity against various pathogenic microorganisms. Indian J Sci Res. 2014; 4(1): 39-44.

23. Rajiv P, Sivara R. Screening for phytochemicals and antimicrobial activity of aqueous extract of Ficus religiosa Linn. Int J Pharm Pharm Sci. 2012; 4(5): 207-9

24. Ramakrishnaiah G, Hariprasad T. In vitro antimicrobial activity of leaves and bark extracts of Ficus religiosa (Linn.). International Research Journal of pharmacy 2012; 3(9): 178-9.

25. Kekuda TRP Mallikarjun N, Swathi D, Nayana KV Aiyar MB, Rohini TR. Antibacterial and antifungal efficacy of steam distillate of Moringa oleifera Lam. J Pharm Sci \& Res. 2010; 2(1): 34-7.

26. Devendra BN, Srinivas N, Prasad VSSL, Talluri, Swarnalatha P. Antimicrobial activity of Moringa oleifera Lam., leaf extract, against selected bacterial and fungal strains. International Journal of Pharma and Bio Sciences. 2011; 2(3): B13- 8.

27. John SA, Selvi BTM. Preliminary phytochemical investigation and antimicrobial activity of Sphaeranthus indicus Linn. Asian Journal of Microbiology, Biotechnology \& Environmental Sciences. 2011; 13(2): 251-6.

28. Meher BR, Mahar S, Rath BG, Sahoo SK. Antimicrobial activity of ethanolic extracts of leaves of Sphaeranthus indicus. Der Pharmacia Lettre. 2013; 5(1): 8-10.

29. Sharanya M, Oviya IR, Poornima V, Jeyam M. Antifungal susceptibility testing of few medicinal plant extracts against Aspergillus spp. and Microsporum sp. Journal of Applied Pharmaceutical Science. 2013; 3(8-S1): S12-6.

30. Taweechaisupapong S, Choopan T, Singhara S, Chatrchaiwiwatana S Wongkham. In vitro inhibitory effect of Streblus asper leaf extract on adhesion of Candida albicans to human buccal epithelial cells. J Ethnopharmacol. 2005; 96(1): 221-6.

31. Gautam K, Kumar P. Extraction and pharmacological evaluation of some extracts of Vitex negundo Linn. Int J Pharm Pharm Sci. 2012; 4(2): 132-7.

32. Devi TS, Padmaja IJ, Harshitha C, Kalyani CS, Lakshmi N, Bhavani AKD. Anti dermatophytic activity on ethnomedical plants used by a primitive tribe "Gadabas" of Paderu. Int J Pharm Bio Sci. 2014; 5(2): 292-9.

33. Badgujar VB, Jain PS, Badgujar SV. Antifungal activity of stem bark of Helicteres isora Linn. Drug Invention Today. 2009; 1(2): 135. 
PICTORIAL ABSTRACT

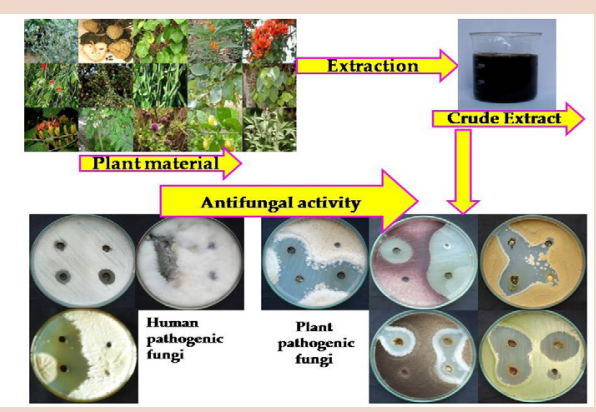

\section{SUMMARY}

- Efficacy of fifteen medicinal plants with crude extracts bearing antifungal activity against phyto pathogenic and human pathogenic fungi.

- Crude extracts of Callistemon lanceolatus displayed significant activity against $C$. albicans and Microsporum gypseum.

- Cordia dichrotoma leaves extracts exhibited significant activity against $A$. niger, A. flavus and C. albicans.

- Sphaeranthus indicus L. whole plant extracts exhibited significant activity against Aspergillus spp., C. albicans and Microsporum canis.

- Leaves extracts of Vitex negundo exhibited significant activity against $A$. niger, A. flavus, F. verticillioides, $C$. albicans and moderate activity against F. crookwellense.

- Extracts of Butea monosperma exhibited significant to moderate activity against all test pathogens except $C$. albicans.

\section{ABOUT AUTHORS}

Dr. Satish Sreedharamurthy: Is a faculty at Department of Studies in Microbiology, Manasagangotri, University of Mysore, Karnataka, India. He has honed various prestigious awards which includes DST-Young Scientist, NESA Scientist of the year, Honored Fellow of FISBT and UGC-Post Doctoral Raman Research Fellow-USA. He is working on interdisciplinary aspect of life sciences and his core area of interest is in the field of Microbiology, Plant biology, Bio-nanotechnology, Molecular Biology. Currently his research groups are working on bioprospecting of medicinal plants, novel endophytes, development of antimicrobial agents and biosynthesis of nanoparticles. His research projects are funded by UGC, DST, IOE. His research contributions are in the form of research articles with more than 70 articles in National and International journals. His research findings are also presented at 80 National and International conferences and Symposia. He has been honored with best poster award at international and national conferences.

Miss Kavitha Kumar: Is a research scholar at Department of Studies in Microbiology, Manasagangotri, University of Mysore, Karnataka, India. Her doctoral studies comprises of bio-prospecting of medicinal plants for developing antimicrobial agents against human and phytopathogens. During her research career she has been awarded University of Mysore- JRF, Rajiv Gandhi National Fellowship- JRF and SRF. Her research findings are in the form of research articles published at various national and international journals. She has also presented her work at various National and International conferences and Symposia. 